\title{
$\mathrm{MIT/BIH} \mathrm{부정맥} \mathrm{데이터베이스를} \mathrm{이용한} \mathrm{다중스케일} \mathrm{기반} \mathrm{피크검출}$ 알고리즘의 검증
}

\section{A assessment of multiscale-based peak detection algorithm using MIT/BIH Arrhythmia Database}

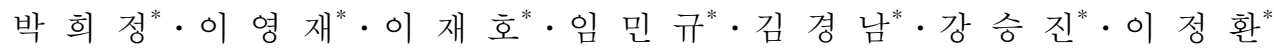 \\ (Hee-Jung Park $\cdot$ Young-Jae Lee $\cdot$ Jae-Ho Lee $\cdot$ Min-Gyu Lim $\cdot$ Kyung-Nam Kim $\cdot$ Seung-Jin \\ Kang $\cdot$ Jeong - whan Lee)
}

\begin{abstract}
A robust new algorithm for $\mathrm{R}$ wave detection named for Multiscale-based Peak Detection(MSPD) is assessed in this paper using MIT/BIH Arrhythmia Database. MSPD algorithm is based on a matrix composed of local maximum and find $\mathrm{R}$ peaks using result of standard deviation in the matrix. Furthermore, By reducing needless procedure of proposed algorithm, improve algorithm ability to detect $\mathrm{R}$ peak efficiently. And algorithm performance is assessed according to detection rates about various arrhythmia database.
\end{abstract}

Key Words : R peak, Multiscale-based Peak detection, Local Maximum Scalogram

\section{1. 서 론}

생체신호처리 분야에서 신호의 피크를 검출하는 과정은 오프라인에서 후처리를 위해서도 매우 중요하므로 여러 가 지 새로운 방법들이 끊임없이 개발되고 있다. 일반적으로 사용되고 있는 피크 검출 방법에는 대표적으로 역치값 설정 기술(Adaptive threshold)[3], 미분(Differentiation)[8], 웨이블 렛 변환(Wavelet transform)[2], 힐버트 변환(Hilbert transform)[11] 등을 바탕으로 하는 알고리즘들이 있다. 하 지만 이 알고리즘들은 신호를 분석하기 전에 상황에 따라서 많은 변수들(역치값[3] 또는 윈도우 길이[4])을 상황에 맞게 수정해야 하는 문제점을 가지고 있다. 알고리즘 적용단계에 서 최적화를 위해 변수에 대한 수작업이 동반되는데, 잘 적 용되는 경우와 잘 적용되지 않는 경우들이 발생하게 된다. 그리고 피크 검출률은 높은 수준의 결과들을 보이지만 계산 양이 많거나, 고주파 잡음에 민감하거나, 요구되는 변수들이 많아 시스템으로 구현하기에는 어려움이 있는 알고리즘들이 대부분이다. 반대로 변수가 거의 필요 없는 알고리즘들은 심전도[5] 같은 비주기적인 스파이크 경향의 신호와 같은 특 별한 경우일 때 낮은 검출률로 인해 사용에 제약이 따른다.

따라서 본 논문에서는 심전도 신호 중에서도 각종 심장질 환을 진단할 때 중요한 척도가 될 수 있는 심전도 신호의 $\mathrm{R}$-피크를 검출하기 위해, Felix Scholkmann[1] 등이 제안한 방법을 사용했다. 제안된 알고리즘은 기존 알고리즘들과는

\footnotetext{
$\uparrow$ Corresponding Author : Dept. of Biomedical Engineering, Konkuk University, Korea. E-mail: jwlee95@kku.ac.kr

* Biomedical Engineering, Konkuk University, Korea. Received : March 03, 2014; Accepted : September 26, 2014
}

달리 상황에 맞게 고려해야 할 변수들이 요구되지 않고, 비 교적 간단하다는 장점을 가지고 있다. 추가적으로 심전도 신호에서의 $\mathrm{R}$ 피크를 검출하는데 불필요한 계산과정을 줄임 으로써 계산량을 줄이고 $\mathrm{R}$ 피크의 특징이 잘 반영되도록 최 적화시킨 후, 이의 성능을 비교 평가하고자 한다.

\section{2. 본 론}

\section{1 심전도(Electrocardiogram)}

심전도[5]는 심장의 전기적 활동을, 체표면에서 측정한 전 기적 신호를 의미한다. 심전도의 한 주기 $(\mathrm{Cycle})$ 는 각각 $\mathrm{P}$, $\mathrm{Q}, \mathrm{R}, \mathrm{S}, \mathrm{T}$ 파(wave)로 구성되어 있다. $\mathrm{P}$ 파는 심방의 탈분 극, $\mathrm{QRS}$ 파는 좌, 우심실의 탈분극, $\mathrm{T}$ 파는 심실의 재분극에 의해 각각 발생한다. 일반적으로 심전도 신호는 호흡 및 전 원 장치로 인하여 신호에 왜곡 현상이 나타난다. 심전도의 주파수대역은 $0.05 \mathrm{~Hz}$ 에서 $100 \mathrm{~Hz}$ 로 대부분 낮은 대역에 형 성되고 있어서, 호흡과 움직임 등에 의한 저주파 잡음에 큰 영향을 받는다. 따라서 필터링을 통해 $\mathrm{QRS}$ 파를 검출해 내 는 것이 중요하다.

\section{2 다중스케일 기반 $\mathrm{R}$ 피크 검출 알고리즘}

본 논문에서 제안하는 다중스케일 기반 피크검출 알고리 즘은 Felix Scholkmann[1] 등에 의하여 처음으로 제안된 방 법으로, 대상 신호에서 국지적 최대값 스칼로그램 (scalogram)을 계산하여 피크 성분이 있는 곳의 위치를 확 률적으로 파악한 뒤, 최종적으로 피크의 위치는 스칼로그램 의 표준편차가 최소가 된다는 점을 이용해 피크를 검출하는 


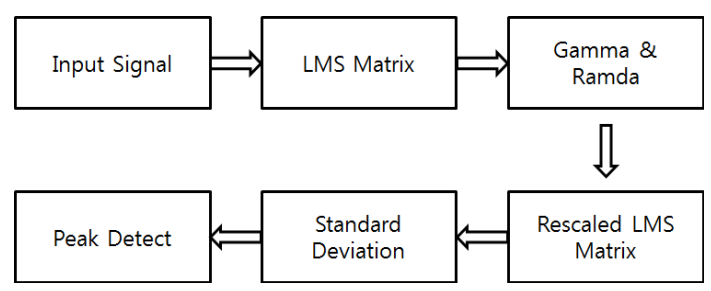

그림 1 다중스케일 기반 $\mathrm{R}$ 피크 검출 알고리즘 흐름도

Fig. 1 Block diagram of proposed peak detection algorithm

알고리즘이다.

\subsection{1 호흡성분을 제거하기 위한 고역통과 필터}

피실험자의 심전도 신호를 10 초간 측정하고 샘플링 주파 수 $120 \mathrm{~Hz}$ 로 양자화 한 뒤, 심전도의 한 주기가 4 개가 포함 되어 있도록 약 4 초간의 심전도 신호를 추출하였다.

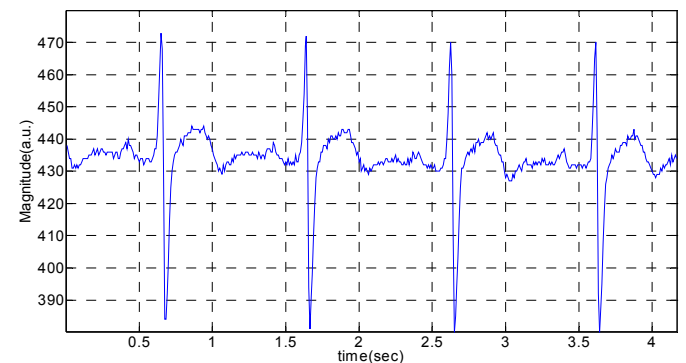

그림 2 피실험자의 심전도 신호

Fig. 2 ECG signal

\subsection{2 국지적 최대값 스케일러그램(Local Maximum Scalogram)}

양의 방향으로 솟아오른 피크의 특징을 이용하기 위하여, 총 길이가 $\mathrm{N}$ 개인 양자화 된 심전도 신호를 $x$ 라 했을 때, $x_{i}$ 를 기준으로 양옆 샘플간격이 $k$ 개인 심전도 신호 3 개 $\left\{x_{i-k}, x_{i}, x_{i+k}\right\}$ 를 식 (1)에 따라 비교해 국지적 최대값 $m_{k, i}$ 을 계산한다. 비교한 세 값 중 $x_{i}$ 가 가장 큰 값이라면 성분 값을 0 이라 하고, 그렇지 않으면 임의의 값 $r+\alpha$ 로 하여 LMS 행렬을 계산한다. 여기서, $r$ 은 0 과 1 사이의 임 의의 값이고, $\alpha$ 는 상수 1 이다. 예를 들어 $i=k+1, \ldots, N-k$ 에 대해, 행렬의 첫 번째 행 $(\mathrm{k}=1)$ 은 $x_{i}$ 를 기준으로 $x_{i-1}$ 과 $x_{i+1}$ 을 비교하고, 두 번째 행 $(\mathrm{k}=2)$ 은 $x_{i}$ 를 기준으로 $x_{i-2}$ 와 $x_{i+2}$ 를 비교하는 방법으로 $\mathrm{N} / 2$ 번째 행까지 만들어진다. 이렇게 만들어진 행렬을 'LMS 행렬' 이라고 하며 식 (2)처 럼 정의한다.

$$
\begin{gathered}
m_{k, i}=\left\{\begin{array}{cl}
0 & \left(x_{i-k}<x_{i}\right) \wedge\left(x_{i+k}<x_{i}\right) \\
r+\alpha & \text { otherwise }
\end{array}\right. \\
\text { LMS Matrix }=\left[\begin{array}{cccc}
m_{1,1} & m_{1,2} & \cdots & m_{1, N} \\
m_{2,1} & m_{2,2} & \cdots & m_{2, N} \\
\vdots & \vdots & \ddots & \vdots \\
m_{L, 1} & m_{L, 2} & \cdots & m_{L, N}
\end{array}\right]
\end{gathered}
$$

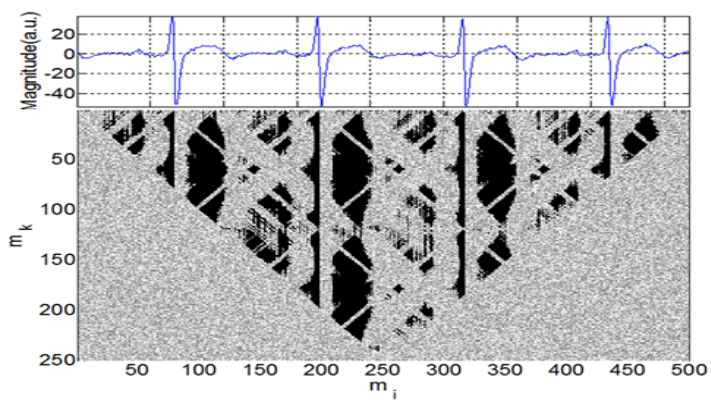

그림 $3 \mathrm{k}$ 간격으로 이격된 샘플을 이용한 LMS 행렬

Fig. 3 LMS Matrix using sample of distant $k$ intervals

그림 3 은 $k$ 간격으로 이격된 샘플을 이용하여 계산된 LMS 행렬을 나타낸 그래프이다. 검은색으로 나타난 성분들 이 값이 0 , 즉 국지적 최대값이다. 따라서 LMS 행렬은 국지 적 최대값의 분포에 대한 정보를 담고 있다.

\subsubsection{Gamma 배열과 Lambda 인덱스의 설정}

다음 단계는 2.2.2절에서 구한 LMS 행렬에 대하여, 다음 의 식 (3)와 같이, 각각의 행(row)을 기준으로 합계를 구한 다. 그 결과 만들어진 배열을 'Gamma 배열'이 라고 정의한 다. Gamma는 국지적 최대값의 분포에 대한 정보를 담고 있 는 중요한 배열이다.

$$
\begin{aligned}
\gamma_{k} & =\sum_{i=1}^{N} m_{k, i} \quad \text { for } k \in 1,2, \cdots, L \\
& =\left[\begin{array}{lllll}
\gamma_{1} & \gamma_{2} & \gamma_{3} & \cdots & \gamma_{L}
\end{array}\right]
\end{aligned}
$$

식 (1)에 의해, LMS 행렬에서 1차적으로 피크성분이라고 추정되는 부분은 그 성분값들이 0 이므로, 식 (3)에 의하여 계산되는 각 행의 총합은 상대적으로 작은 값을 가지는 중 요한 성질을 확인 할 수 있다(그림 4).

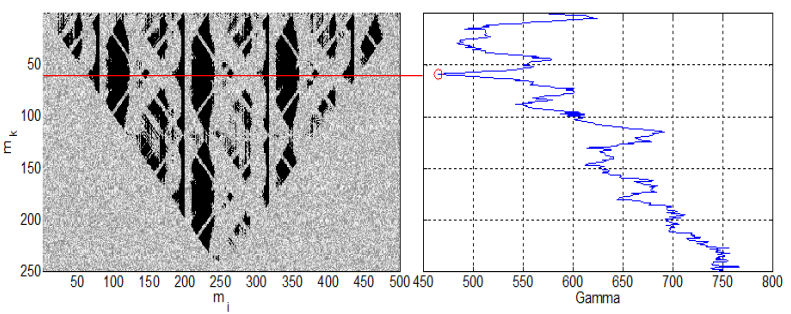

그림 $4 \mathrm{LMS}$ 배열에서 각각의 행을 기준으로 한 Gamma배열 Fig. 4 Gamma array based on row criteria in LMS matrix

Gamma 배열의 값 중 최소값을 가질 때의 인덱스를 'Lambda $(\lambda)$ 인덱스' 라고 정의한다. 그림 3 에서 볼 수 있듯 이, $\lambda=60$ 인 경우, LMS 행렬의 어떤 한 데이터(열)가 주기 적으로 반복되는 피크들 중 하나라면 60 번째 행까지 그 열 의 성분값 $m_{k, i}$ 가 0 이라는 것을 뜻함과 동시에, 이 데이터의 양옆 샘플간격이 60 개 내에는 자신보다 큰 값이 없다는 의 미가 되므로 Lambda 인덱스는 샘플간격과 연관되어 있음을 
알 수 있다.

\subsection{4 축소된 LMS 행렬(Reduced LMS matrix)}

앞에서 구한 LMS 행렬은 행의 범위가 $\{1,2, \cdots, N / 2\}$, 열의 범위가 $\{1,2, \cdots, N\}$ 에 이른다. 여기서 2.2.3절에서 구 한 Lambda 인 덱스를 적용시켜 행의 범위를 $\{1,2, \cdots, \lambda\}$ 로 축소할 수 있다. 이 축소된 행렬을 “축소된 LMS 행렬 (RLMS matrix)”이라고 정의한다.

$$
M_{r}=\left(m_{k, i}\right) \quad \text { for } k=1,2, \cdots, \lambda
$$

그림 4 의 왼쪽 그림은 축소되기 이전 LMS 행렬, 오른쪽 그림은 축소된 이후의 LMS 행렬을 나타낸다. LMS 행렬을 축소하게 되면 오른쪽 그림의 빨간색 네모박스와 같은 특징 이 드러난다. 각 열의 요소값이 모두 0을 나타내고 있다. 이 특징을 이용해 다음 절에서 피크의 위치를 검출해낼 수 있다.
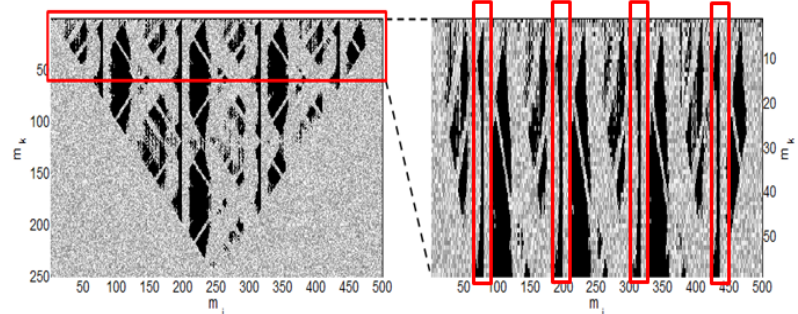

그림 5 기존 LMS 행렬(좌),축소된 LMS 행렬(우)

Fig. 5 LMS Matrix (L), Rescaled LMS Matrix(R)

\subsubsection{RLMS 행렬 열(column) 표준편차의 계산과 $\mathrm{R}$ 피크의 위치}

다음 식 (5)와 같이 축소된 LMS 행렬의 열(column)을 기 준으로 표준편차를 구함으로써 $\mathrm{R}$ 피크의 위치를 추정할 수 있다.

$\sigma_{i}=\frac{1}{\lambda-1}\left[\sum_{k=1}^{\lambda}\left(m_{k, i}-\frac{1}{\lambda} \sum_{k=1}^{\lambda} m_{k, i}\right)^{2}\right]^{\frac{1}{2}}$ for $i \in 1,2, \cdots, N$

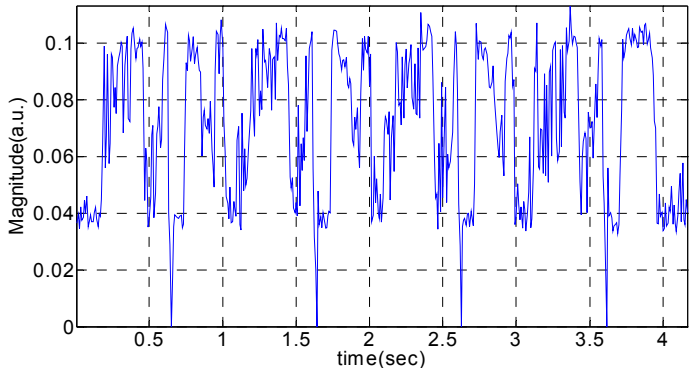

그림 6 축소된 LMS 행렬에서 열(column) 기준의 표준편차

Fig. 6 Standard deviation of Rescaled LMS Matrix
예를 들어, 100 번 째 열의 데이터가 찾고자 하는 심전도 의 R피크일 때, LMS 행렬에서 1 행 $\lambda$ 행까지 모두 $m_{k, 100}=0$ 이므로 표준편차 $\sigma_{100}$ 또한 0이다. 그 결과 100번 째 열의 데이터를 $\mathrm{R}$ 피크라고 인식하게 된다(그림 6).

그림 7은 축소된 LMS 행렬에서 열(column)을 기준으로 계산한 표준편차 $\sigma_{i}$ 중에 $\sigma_{i}=0$ 일 때의 $\mathrm{i}$ 값만 배열로 구성 하여 ECG 원본 신호와 매칭 시킨 결과를 나타낸다.

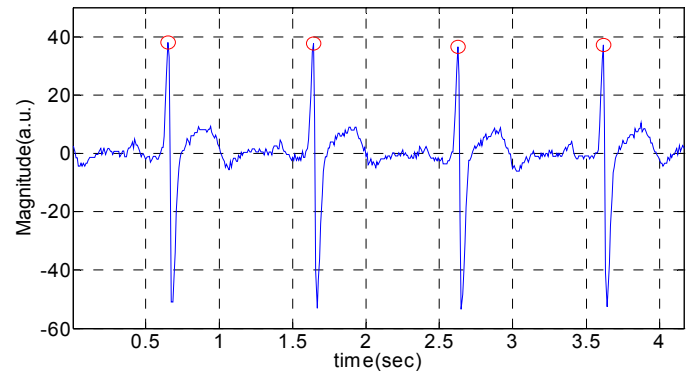

그림 7 표준편차 $\sigma_{i}=0$ 와 신전도 신호 $\mathrm{R}$ 피크와의 관계

Fig. 7 Detection result of $R$ peak

정확한 $\mathrm{R}$ 피크를 검출하기 위해서는 Lambda 인덱스 값이 어느 범위에 있는지가 중요한 요소로 작용한다. 만약 정확 한 R피크를 검출하기 위한 Lambda 인덱스 값이 60 인데, 60 이하의 값이 나오면 실제 피크인 위치에서 표준편차가 0이 나오지 않아 $\mathrm{R}$ 피크를 놓치는 경우가 발생한다. 반대로 Lambda 인덱스 값이 60 이상이면 $\mathrm{R}$ 피크는 물론이고 $\mathrm{P}$ 파나 $\mathrm{T}$ 파의 위치까지도 표준편차가 0 이 나오게 되므로 원하지 않은 피크까지 검출되는 문제가 발생할 수 있는 가능성이 있다.

\section{3 알고리즘 최적화}

이런 과정을 통해 생체 신호의 피크 위치를 검출해낼 수 있다. 그러나 일반적인 신호에서의 피크성분을 검출하기 위 하여 버퍼로 사용하는 메모리 공간이 과다하게 많으며, 심전 도 신호의 경우, 심전도 신호의 특성이 반영이 되지 않는 경 우가 많으므로 알고리즘을 심전도에 그대로 적용하기에는 무리가 있다. 따라서 심전도 신호에서의 $\mathrm{R}$ 피크 검출을 위해 서는 계산량을 줄이고 심전도의 특성이 잘 반영되기 위한 최적화가 필요하다.

\subsubsection{P 파, T파를 제외시키기 위한 Gamma 범위 축소}

심전도의 $\mathrm{QRS}$ 파뿐만 아니라 $\mathrm{P}$ 파와 $\mathrm{T}$ 파 또한 주기적인 성향을 가지고 있으므로, 제안한 $\mathrm{MSPD}$ 알고리즘은 $\mathrm{P}$ 와 $\mathrm{T}$ 파 또한 피크로 인식할 가능성이 있다. 따라서 $\mathrm{P}$ 파와 $\mathrm{T}$ 파가 검출되지 않는 범위로 $m_{k}$ 를 수정할 필요가 있다. 이를 위하 여, 실험적으로 $m_{k}$ 를 다음의 식 (6)과 같이 제한하였다. $m_{k}$ 의 범위를 축소시킨 후에 Gamma 배열과 Lambda 인덱스를 찾는 과정을 진행한다.

$f_{s} / 3.5<m_{k}<f_{s} / 1.5$ 


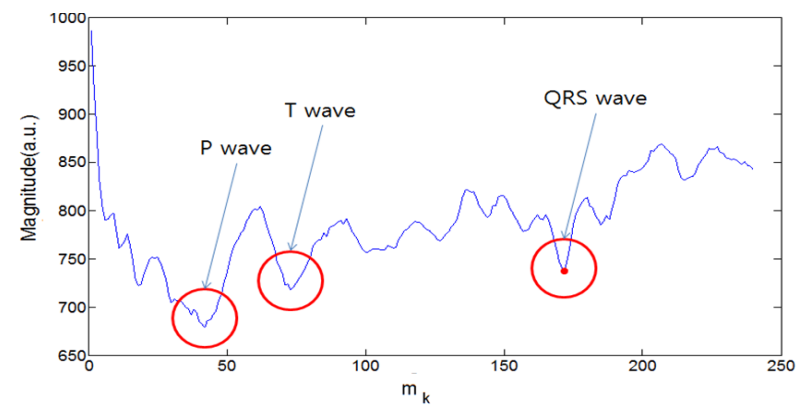

그림 8 Gamma에 나타난 심전도특성

Fig. 8 ECG Characteristics in Gamma

정상적인 심전도의 경우 $\mathrm{P}$ 파의 특성은 $m_{k}=40, \mathrm{~T}$ 파의 특 성이 $m_{k}=75$ 부근에서 나타난 모습을 볼 수 있다. $\mathrm{MIT} / \mathrm{BIH}$ Arrhythmia Database의 심전도 데이터는 $f_{s}=360 \mathrm{~Hz}$ 이므로, $m_{k}$ 의 범위는 $102 \sim 240$ 로 축소된다. 따라서 제안한 알고리즘은 일반적인 $\mathrm{R}$ 피크일 경우, $\mathrm{P}$ 와 $\mathrm{T}$ 파는 검출되지 않고 $\mathrm{R}$ 피크만 검출한다.

\subsection{2 구간 overlapping}

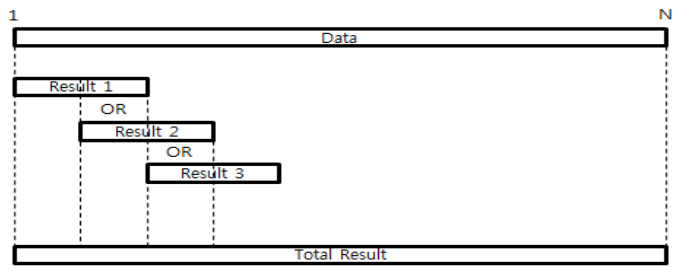

그림 9 Overlapping 흐름도

Fig. 9 Overlapping Block diagram

또한 제안한 알고리즘은 메모리 사용의 효율성을 향상시 키기 위하여, 전체 심전도 데이터를 한 번에 처리하지 않고, window의 크기를 1000 개로 고정시켜 심전도 샘플구간을 나 눠서 피크를 검출했다. 전체 데이터가 $\mathrm{N}$ 개 일 때, 구간을 $1 \sim 1000, \quad 501 \sim 1500, \quad 1001 \sim 2000, \ldots, \quad(\mathrm{N}-999) \sim \mathrm{N}$ 으로 나누 고, 겹치는 구간(501 1000)구간은 앞 구간(1 1000)에서 검 출된 피크와 뒷 구간(501 1500)에서 검출된 피크를 OR연산 을 통해 결정해준다. 그림 10 은 데이터 샘플의 중첩과정의 유무에 따른 $\mathrm{R}$ 피크 검출 결과를 나타낸다.

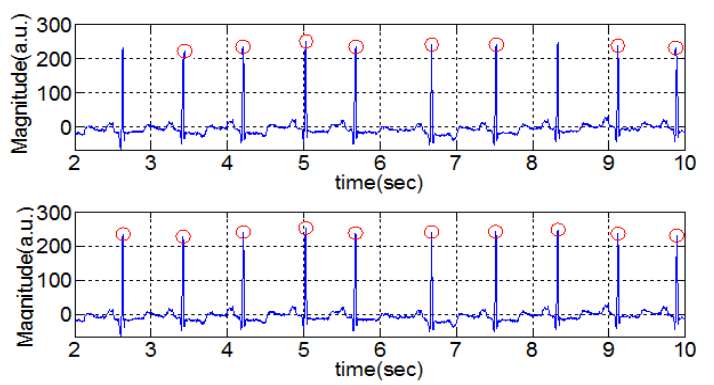

그림 10 Overlap 하지 않았을 때(위), Overlap 했을 때(아래) Fig. 10 No overlap(up), overlap(down)
데이터의 전체길이가 길어 한 번에 알고리즘을 처리하기 에는 다소 무리가 있으므로 구간을 나누어 알고리즘에 적용 시킨다. 그리고 이에 따라 발생하는 문제는 원도우 크기에 따라 구간이 나눠지는 경계에 근접해 있는 $\mathrm{R}$ 피크가 검출되 지 않은 결과를 그림 10 의 위 그림에서 볼 수 있으나, 중첩 처리를 적용함으로써 $\mathrm{R}$ 피크 검출의 정확도를 높일 수 있다.

\subsubsection{QRS파 검출을 위한 대역통과 필터}

QRS파의 주파수 대역만 통과시키기 위해 Butterworth $8 \sim 20 \mathrm{~Hz}$ 대역의 대역통과 1 차 필터를 적용시켰다. QRS파를 검출하기 위해 제안된 차단주파수 대역은 다음과 같다. Thakor[6]와 Chen[7] 5 15Hz, Pan and Tompkins[8] 5 $11 \mathrm{~Hz}$, Cuiwei[9] 8 58.8Hz, Sahambi[10] 3 40Hz, Benitez[11] 8 20Hz, Moraes[12] 9 30Hz, Mahmoodabadi[13] 2 40Hz. 논문에 제시된 대역을 알고리즘에 적용시켜본 결과 8 $20 \mathrm{~Hz}$ 의 경우가 가장 효율적이었다. 결과는 표 4 에서 확인할 수 있다.

\section{3. 결 과}

심전도의 $\mathrm{R}$ 피크 검출 성능을 평가하기 위하여 $\mathrm{MIT} / \mathrm{BIH}$ Arrhythmia Database에서 제공하는 약 1 시간 길이의 48 개 2 채널 심전도 신호 중, 첫 번째 채널을 사용하였다. 피험자 1 명당 데이터 개수는 650000개이다. MIT/BIH Arrhythmia Database는 Annotation R피크 정보 또한 제공해 주기 때문 에, 알고리즘이 찾아낸 $\mathrm{R}$ 피크가 정확한지 아닌지를 확인할 수 있다. 피크검출 알고리즘의 성능을 판단하기 위해 검출 결과를 표 1에 제시된 조건(Condition)과 검출결과(Test)에 따라 True Positive, False Positive, False Negative, True Negative로 나눈 후, 그 결과를 표 2에 제시된 평가기준에

표 1 분할표[15]

Table 1 Contingency table

\begin{tabular}{|c|c|c|}
\hline & Condition(+) & Condition(-) \\
\hline Test $(+)$ & TP(True Positive) & FP(False Positive) \\
\hline Test $(-)$ & FN(False Negative) & TN(True Negative) \\
\hline
\end{tabular}

표 2 분할표를 이용한 평가기준

Table 2 Appraisal standard using contingency table

\begin{tabular}{|c|c|}
\hline & 정의 \\
\hline $\begin{array}{c}\text { 예측도 } \\
\text { (Positive predictive } \\
\text { value: +P) }\end{array}$ & $\frac{T P}{T P+F P} \times 100$ \\
\hline $\begin{array}{c}\text { 민감도 } \\
\text { (Sensitivity : SE) }\end{array}$ & $\frac{T P}{T P+F N} \times 100$ \\
\hline $\begin{array}{c}\text { 특이성 } \\
\text { (Specificity : SP) }\end{array}$ & $\frac{T N}{F P+T N} \times 100$ \\
\hline 정확도 \\
(Accuracy : $\mathrm{AC}$ ) & $\frac{T P+T N}{T P+F P+F N+T N} \times 100$ \\
\hline
\end{tabular}


적용시킨다. 이 결과를 통해 알고리즘이 얼마나 효과적으로 $\mathrm{R}$ 피크를 검출했는지 알 수 있다. $\mathrm{TP}($ True Positive)는 Annotation에 제시된 샘플번호를 기준으로 샘플 개수 40개 이내로 피크가 검출되었을 경우 $\mathrm{TP}$ 라고 설정하였다. 마찬가 지로 $\mathrm{FP}, \mathrm{FN}, \mathrm{TN}$ 또한 표 2 의 정의에 따라 검출결과를 설 정했다.

표 2 를 $\mathrm{R}$ 피크 검출 알고리즘에 적용해 설명하면, 예측도 는 알고리즘에 의해서 피크라고 검출된 것 중 실제 피크가 얼마나 들어있는지에 대한 비율을 의미한다. 민감도는 실제 피크 중 알고리즘에 의해 몇 개나 검출되었는지에 대한 비 율이다. 특이성은 피크가 아닌 것 중 알고리즘에 의해 피크 가 아니라고 검출된 것의 비율이다. 정확도는 전체 샘플에 대해서 알고리즘이 정확하게 피크인 것과 아닌 것을 구분했 는지에 대한 확률이다.

표 3은 본 논문에서 제안한 방법으로 피크 검출 알고리즘 을 최적화 시킨 후, MIT/BIH Arrhythmia Database에 적용 하여 얻어진 R피크 검출 결과를 나타낸다.

표 4는 주파수 대역별 예측도와 민감도 결과만 정리한 것 이다. 이를 보아 알 수 있는 것은 대역통과 필터를 사용하

표 $\quad 3 \mathrm{MIT} / \mathrm{BIH}$ arrhythmia database에서의 $\mathrm{R}$ 피크 검출 결과 Table 3 Detection results on $\mathrm{MIT/BIH}$ arrhythmia database

\begin{tabular}{|c|c|c|c|c|c|c|c|c|c|}
\hline File & Beats & TP & $F P$ & $\mathrm{FN}$ & $\mathrm{TN}$ & $+\mathrm{P}(\%)$ & $\mathrm{SE}(\%)$ & $\mathrm{SP}(\%)$ & $\mathrm{AC}(\%)$ \\
\hline 100 & 2273 & 2271 & 1 & 2 & 647726 & 99.96 & 99.61 & 99.99 & 99.99 \\
\hline 101 & 1863 & 1861 & 11 & 2 & 648126 & 99.41 & 99.89 & 99.99 & 99.99 \\
\hline 102 & 2187 & 2186 & 20 & 1 & 647793 & 99.54 & 99.95 & 99.99 & 99.99 \\
\hline 103 & 2084 & 2083 & 0 & 1 & 647916 & 100 & 99.95 & 100 & 99.99 \\
\hline 104 & 2211 & 2203 & 43 & 8 & 647746 & 98.09 & 99.64 & 99.99 & 99.99 \\
\hline 105 & 2567 & 2543 & 43 & 24 & 647390 & 98.34 & 99.07 & 99.99 & 99.98 \\
\hline 106 & 2027 & 2010 & 91 & 17 & 647882 & 95.67 & 99.16 & 99.98 & 99.98 \\
\hline 107 & 2137 & 2136 & 8 & 1 & 647855 & 99.63 & 99.95 & 99.99 & 99.99 \\
\hline 108 & 1763 & 1761 & 76 & 2 & 648161 & 95.86 & 99.89 & 99.98 & 99.98 \\
\hline 109 & 2532 & 2530 & 0 & 2 & 647468 & 100 & 99.92 & 100 & 99.99 \\
\hline 111 & 2124 & 2124 & 2 & 0 & 647874 & 99.91 & 100 & 99.99 & 99.99 \\
\hline 112 & 2539 & 2537 & 0 & 2 & 647461 & 100 & 99.92 & 100 & 99.99 \\
\hline 113 & 1789 & 1788 & 5 & 1 & 648206 & 99.72 & 99.94 & 99.99 & 99.99 \\
\hline 114 & 1879 & 1879 & 31 & 0 & 648090 & 98.38 & 100 & 99.99 & 99.99 \\
\hline 115 & 1953 & 1952 & 29 & 1 & 648018 & 98.54 & 99.95 & 99.99 & 99.99 \\
\hline 116 & 2412 & 2400 & 11 & 12 & 647577 & 99.54 & 99.5 & 99.99 & 99.99 \\
\hline 117 & 1535 & 1533 & 30 & 2 & 648435 & 98.08 & 99.87 & 99.99 & 99.99 \\
\hline 118 & 2278 & 2275 & 6 & 3 & 647716 & 99.74 & 99.87 & 99.99 & 99.99 \\
\hline 119 & 1987 & 1987 & 489 & 0 & 647524 & 80.25 & 100 & 99.92 & 99.92 \\
\hline 121 & 1863 & 1863 & 54 & 0 & 648083 & 97.18 & 100 & 99.99 & 99.99 \\
\hline 122 & 2476 & 2474 & 0 & 2 & 647524 & 100 & 99.92 & 100 & 99.99 \\
\hline 123 & 1518 & 1517 & 11 & 1 & 648471 & 99.28 & 99.93 & 99.99 & 99.99 \\
\hline 124 & 1619 & 1609 & 29 & 10 & 648352 & 98.23 & 99.38 & 99.99 & 99.99 \\
\hline 200 & 2601 & 2590 & 71 & 11 & 647328 & 97.33 & 99.58 & 99.98 & 99.98 \\
\hline 201 & 1866 & 1780 & 327 & 86 & 647807 & 84.48 & 95.39 & 99.94 & 99.93 \\
\hline 202 & 2117 & 2100 & 86 & 17 & 647797 & 96.07 & 99.2 & 99.98 & 99.98 \\
\hline 203 & 2974 & 2864 & 105 & 110 & 646921 & 96.46 & 96.3 & 99.98 & 99.96 \\
\hline 205 & 2656 & 2638 & 0 & 18 & 647344 & 100 & 99.32 & 100 & 99.99 \\
\hline 207 & 1860 & 1836 & 491 & 24 & 647649 & 78.9 & 98.71 & 99.92 & 99.92 \\
\hline 208 & 2953 & 2941 & 13 & 12 & 647034 & 99.56 & 99.59 & 99.99 & 99.99 \\
\hline 209 & 3005 & 3002 & 0 & 3 & 646995 & 100 & 99.9 & 100 & 99.99 \\
\hline 210 & 2628 & 2621 & 38 & 7 & 647334 & 98.57 & 99.73 & 99.99 & 99.99 \\
\hline 212 & 2748 & 2747 & 1 & 1 & 647251 & 99.96 & 99.96 & 99.99 & 99.99 \\
\hline 213 & 3248 & 3244 & 3 & 4 & 646749 & 99.91 & 99.88 & 99.99 & 99.99 \\
\hline 214 & 2260 & 2228 & 194 & 32 & 647546 & 91.99 & 98.58 & 99.97 & 99.96 \\
\hline 215 & 3363 & 3351 & 0 & 12 & 646637 & 100 & 99.64 & 100 & 99.99 \\
\hline 217 & 2208 & 2197 & 238 & 11 & 647554 & 90.23 & 99.5 & 99.96 & 99.96 \\
\hline 219 & 2154 & 2154 & 314 & 0 & 647532 & 87.28 & 100 & 99.95 & 99.95 \\
\hline 220 & 2048 & 2045 & 7 & 3 & 647945 & 99.66 & 99.85 & 99.99 & 99.99 \\
\hline 221 & 2427 & 2424 & 64 & 3 & 647509 & 97.43 & 99.88 & 99.99 & 99.98 \\
\hline 222 & 2483 & 2463 & 174 & 20 & 647343 & 93.4 & 99.19 & 99.97 & 99.97 \\
\hline 223 & 2604 & 2602 & 6 & 2 & 647390 & 99.77 & 99.92 & 99.99 & 99.99 \\
\hline 228 & 2053 & 2030 & 120 & 23 & 647827 & 94.42 & 98.88 & 99.98 & 99.97 \\
\hline 230 & 2256 & 2255 & 4 & 1 & 647740 & 99.82 & 99.96 & 99.99 & 99.99 \\
\hline 231 & 1571 & 1571 & 536 & 0 & 647893 & 74.56 & 100 & 99.91 & 99.91 \\
\hline 232 & 1780 & 1779 & 540 & 1 & 647680 & 76.71 & 99.94 & 99.91 & 99.91 \\
\hline 233 & 3079 & 3069 & 0 & 10 & 646921 & 100 & 99.68 & 100 & 99.99 \\
\hline \multirow[t]{2}{*}{234} & 2753 & 2753 & 0 & 0 & 647247 & 100 & 100 & 100 & 100 \\
\hline & & & & & & 96.17 & 99.54 & 99.98 & 99.98 \\
\hline
\end{tabular}

지 않은 경우에 예측도 $(+\mathrm{P})$ 88.82\%와 민감도(SE) $94.32 \%$ 로, 가장 낮은 검출율을 보였다. 그리고 필터를 사용한 경우, $8 \sim 20 \mathrm{~Hz}$ 의 대역을 가진 필터에서 예측도 $(+\mathrm{P}) \quad 96.17 \%$ 와 민 감도 $(\mathrm{SE}) 99.54 \%$ 로 가장 높은 검출 결과를 얻을 수 있었다.

표 $4 \mathrm{BPF}$ 주파수 대역별 예측도와 민감도 결과

Table $4+P$ and SE results on BPF frequency ranges

\begin{tabular}{|c|c|c|}
\hline Freq. bandwidth(Hz) & $+\mathrm{P}(\%)$ & $\mathrm{SE}(\%)$ \\
\hline No filtering & 88.82 & 94.32 \\
\hline $2 \sim 40$ & 90.8 & 98.2 \\
\hline $3 \sim 40$ & 91.71 & 98.78 \\
\hline $5 \sim 11$ & 91.11 & 94.31 \\
\hline $5 \sim 15$ & 94 & 98.47 \\
\hline $8 \sim 20$ & 96.18 & 99.54 \\
\hline $8 \sim 58.5$ & 92.91 & 99.41 \\
\hline $9 \sim 30$ & 94.9 & 99.52 \\
\hline
\end{tabular}

그러나 본 논문에서 제안한 알고리즘이 모든 경우에 대하 여, 최적화된 결과를 보여주는 것은 아니다. 다음의 그림 11 은 정확한 피크검출이 어려운 심전도 신호의 예를 보여주고 있다.

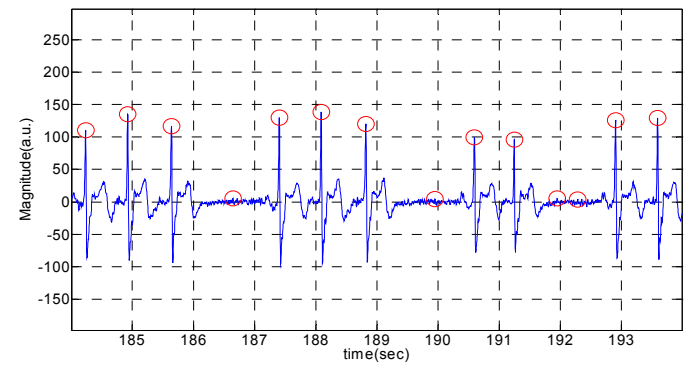

그림 11 정확한 $\mathrm{R}$ 피크를 검출하기 어려운 경우

Fig. 11 Bad case to detect $\mathrm{R}$ peak

일반적으로 심전도 신호가 구분이 명확한 $\mathrm{P}-\mathrm{QRS}-\mathrm{T}$ 파 의 형태를 가지고 있으면 검출 정확도가 매우 높게 나타나 나, 그림 11 처럼 비정상적인 파형을 가지고 있을 때는 검출 율이 상대적으로 낮게 나오는 경향이 있다.

기존의 문헌에서 제안된 대표적인 $\mathrm{R}$ 피크 검출 알고리즘 과 본 논문에서 제안한 알고리즘의 $\mathrm{R}$ 피크 검출결과를 비교 해 보았을 때, 예측도 $(+\mathrm{P})$ 는 약 $3 \%$ 정도 차이가 났으며 민감 도 $(\mathrm{SE})$ 는 큰 차이가 없는 것을 확인 할 수 있었다.

표 5 다른 $\mathrm{R}$ 피크 검출 알고리즘의 $+\mathrm{P}$ 와 $\mathrm{SE}$ Table 5 Contingency table

\begin{tabular}{|l|c|c|}
\hline & $+P(\%)$ & SE(\%) \\
\hline MSPD & 96.17 & 99.54 \\
\hline Wavelet Transform [9] & 99.94 & 99.90 \\
\hline Hilbert Transform[14] & 99.83 & 99.81 \\
\hline Time-averaged algorithm[16] & 99.77 & 99.69 \\
\hline
\end{tabular}

\section{4. 결 론}

본 논문에서는 국지적 최대값 스케일러그램을 구해 피크 
의 위치를 검출해내는 새로운 $\mathrm{R}$ 피크 검출 방법을 $\mathrm{MIT} / \mathrm{BIH}$ 부정맥 데이터에 적용시켜 보았다. 그 결과, 부정맥 같은 불 규칙한 피크가 갑자기 나타나거나, 베이스라인이 흔들려도 유사한 크기의 피크만 주기적으로 나온다면 무리 없이 검출 할 수 있다. 차단주파수가 $0.1 \mathrm{~Hz}$ 인 고역통과 필터를 추가해 호흡에 의한 잡음을 없애주고, $\mathrm{QRS}$ 파 검출을 위한 $8 \sim 20 \mathrm{~Hz}$ 의 대역통과 필터를 추가함으로써 알고리즘을 최적화시킬 수 있다. 실제로 부정맥 데이터를 적용시켜 보았을 때, $+\mathrm{P}$ 와 $\mathrm{SE}$ 가 각각 $96.17 \%, 99.53 \%$ 로 최적화과정을 거치기전 보다 더 정확한 피크 검출이 가능했다.

$\mathrm{R}$ 피크를 찾는 다른 기존의 방법들과 비교해보았을 때, 제 시된 알고리즘은 다음과 같은 특징을 가진다. 첫 번째, 신호 를 분석하기 전에 사용자에 의해 선택되어져야 하는 변수가 필요 없다. 두 번째, 주기적인 성향을 가진 신호에서 정확한 피크를 검출할 수 있다. 이러한 이유로 제시된 알고리즘은 $\mathrm{R}$ 피크 검출에 대해 고효율 알고리즘이다.

제안한 알고리즘은 심전도뿐만 아니라, 다양한 전기적 생 체 신호에 위와 같은 알고리즘을 적용시켜, 효과적인 검출을 할 수 있을 것이다. 그리고 알고리즘을 더욱 단축시킨다면 실시간 $\mathrm{R}$ 피크 검출이 가능할 것이다. 이렇게 다양한 생체신 호를 수집하여, 정확한 검출이 가능한 자동화 시스템을 개발 한다면 $\mathrm{u}$-health 산업을 크게 발전시킬 수 있을 것이다.

\section{감사의 글}

본 연구는 교육부와 한국연구재단의 지역혁신인력양성 사업으로 수행된 연구결과임 (No. 2012H1B8A2025502)

\section{References}

[1] Felix Scholkmann, "An Efficient Algorithm for Automatic Peak Detection in Noisy Periodic and Quasi-Periodic Signals”, MDPI, 5, pp. 588-603, 2012

[2] Li C, Zheng C, Tai C, "Detection of ECG characteristic points using wavelet transforms", IEEE, 42, pp. 21-28, 1995

[3] Jacobsen, A.L, "Auto-Threshold peak detection in physiological signals”, IEEE, 3, pp. 2094-2195, 2001

[4] G. Palshikar. "Simple algorithms for peak detection in time-series." Proc. 1st Int. Conf. Advanced Data Analysis, Business Analytics and Intelligence, 2009

[5] Miri Ha, Hyuk Lee and Byonghyo Shim, "R peak detection based on weighted biorthogonal spline wavelet transform in ECG signal." Conference on Information and Control Systems, pp. 91-92, 2009

[6] THAKOR, N. V., WEBSTER, J. G., TOMPKINS, W. J., "Optimal QRS detector", Medical and Biological Engineering, 21, pp. 343-350, 1983

[7] CHEN, H. C., CHEN, S. W., "A moving average based filtering system with its application to real-time QRS detection”, Computers in Cadiology, pp. 585-588, 2003

[8] PAN, J. \& TOMPKINS, W. J., “A Real-Time QRS Detection Algorithm”, Biomedical Engineering, IEEE Transactions on, BME, 32, pp. 230-236, 1985

[9] CUIWEI, L., CHONGZUN, Z., CHANGFENG, T., "Detection of ECG characteristic points using wavelet transforms", Biomedical Engineering, IEEE Transactions on, 42, pp. 21-28, 1995

[10] J.S. Sahambi, S.N. Tandon, and R.K.P. Bhatt, "Using wavelet transforms for ECG characterization", An on-line digital signal processing system. Engineering in Medicine and Biology Magazine, IEEE, 16, pp. 77-83, 1997

[11] D. S. Benitez, "A new QRS detection algorithm based on the Hilbert transform", Computers in Cardiology, 27, pp. 379-382, 2000

[12] J. Moraes, M. Freitas, F. Vilani, and E. Costa, "A QRS complex detection algorithm using electrocardiogram leads", Computers in Cardiology, 29, pp. 205-208, 2002

[13] MAHMOODABADI, S. Z., AHMADIAN, A., ABOLHASANI, M. D., "ECG Feature Extraction Using Daubechies Wavelets", In : Proceedings of the Fifth IASTED International Conference Visualization, Imaging, and Image Processing, pp. 343-348, 2005

[14] DS BENITEZ, PA GAYDECKI, A ZAIDI, AP FITZPATRICK, "A New QRS Detection Algorithm Based on the Hilbert Transform”, IEEE Computers in Cardiology, 27, pp. 379-382, 2000

[15] Etienne Aliot, Rémi Nitzsché, Alain Ripart, "Arrhythmia detection by dual-chamber implantable cardioverter defibrillators”, Europace, 6, 4, pp.273-286, 2004

[16] PATRICK S. HAMILTON and WILLIS J. TOMPKINS, "Quantitative Investigation of QRS Detection Rules Using the MIT/BIH Arrhythmia Database", IEEE TRANSACTIONS ON BIOMEDICAL ENGINEERING, vol. BME-33, no. 12, 1986
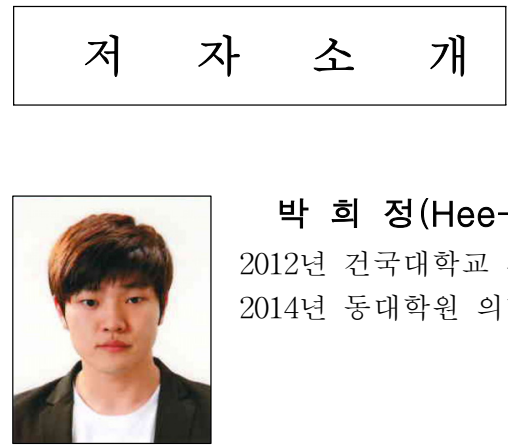

박 희 정(Hee-Jung Park) 2012년 건국대학교 의학공학부 졸업 2014년 동대학원 의학공학부 석사 


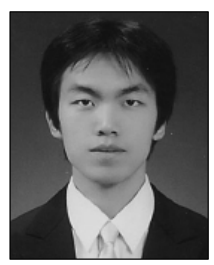

이 영 재(Young-Jae Lee)

2008년 건국대학교 의학공학부 졸업 2010년 동대학원 의학공학부 석사 2010년 현재 동대학원 박사과정

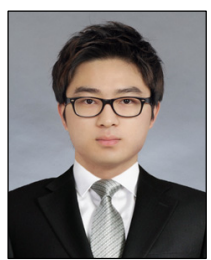

\section{이 재 호(Jae-Ho Lee)}

2012년 건국대학교 의학공학부 졸업 2014년 동대학원 의학공학부 석사

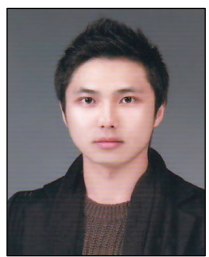

\section{임 민 규(Min-Gyu Lim)}

2012년 건국대학교 의학공학부 졸업 2014년 동대학원 의학공학부 석사

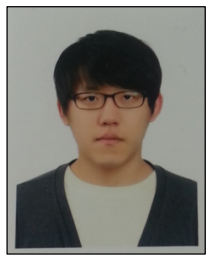

김 경 남(Kyung-Nam Kim) 2014년 건국대학교 의학공학부 졸업 2014년 현재 동대학원 석사과정

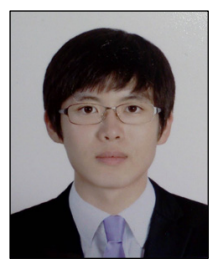

\section{강 승 진(Seung-Jin Kang)} 2014년 건국대학교 의학공학부 졸업 2014년 현재 동대학원 석사과정

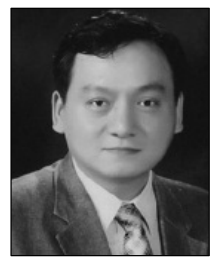

이 정 환(Jeong-whan Lee) 1992년 연세대학교 전기공학과 졸업 1994년 동대학원 석사 2000년 동대학원 박사 2004년 현재 건국대학교 의학공학부 교 수 